\title{
Modeling and Analysis of an Auto- Adjustable Stroke End Cushioning Device for Hydraulic Cylinders
}

C. Schwartz

V. J. De Negri

and J. V. Climaco

Federal University of Santa Catarina Mechanical Engineering Department

Caixa Postal 476

Campus Universitário - Trindade

88040-900 Florianópolis, SC - Brazil

schwartzc@pop.com.br

victor@emc.ufsc.br

climaco@emc.ufsc.br

This paper describes the theoretical-experimental study of an auto-adjustable stroke end cushioning device utilized in hydraulic cylinders, focusing the characterization of the bush geometry effect on the cushioning achieved. A nonlinear model is presented which includes the physical phenomena that exert a significant influence on the performance of this hydraulic component, such as: friction, fluid compressibility and pressure energy loss in the cushioning section. The model is validated through the comparison between theoretical and experimental results, under different conditions of load, supply pressure and piston speed. From this point it is possible to obtain a model applicable for the design of stroke end cushioning devices in hydraulic cylinders. Consequent contributions related to proportional directional valves modeling are also presented.

Keywords: Hydraulic cylinders, cushioning, proportional valves

\section{Introduction}

Over the years hydraulic circuits have been of great importance in the automation and control of machines and equipment, both in industrial and mobile fields. Since service and process requirements are getting more rigid, hydraulic components have been developed in such a way as to increase their reliability in all applications. This may be achieved through combining electronic processing with mechanical components, improving manufacturing processes or new constructive solutions for fluid flow control.

Stroke end cushioning devices are used in hydraulic cylinders moving high inertial loads and/or when speeds are greater than 0.1 $\mathrm{m} / \mathrm{s}$. As a stroke end cushioning device is used to reduce shocks against the cylinder head, it must reduce the kinetic energy acquired by the piston-rod-load set during its operation (LINSINGEN, 2001).

The most common cushioning system used nowadays, despite the emergence of new technologies, consists of a reducing valve and a non-return valve. Alternatively, an auto-adjustable device may be used which is characterized by its simplicity of construction. Its geometric shape derives from load type and the operational requirements of the machine in which the hydraulic cylinder is installed.

The critical design requirement for the auto-adjustable device is to brake the piston in the best possible way, allowing the piston to reach the stroke end with a speed of less than $0.1 \mathrm{~m} / \mathrm{s}$, avoiding excessive pressure peaks during the cushioning and providing gradual speed reduction.

In this context, this paper describes the mathematical model and the proper experimental procedures for the evaluation of the autoadjustable stroke end cushioning device performance under dynamic operational conditions. In addition to the hydraulic cylinder and its load modeling, this paper contributes to the understanding of proportional directional valve behavior related to the parametric variation due to the operational conditions.

Hydraulic cylinder modeling, which incorporates an autoadjustable stroke end cushioning device, and proportional valve modeling used to set the cylinder in motion, are based on classic mechanics and fluid mechanics equations, using experimental parameters obtained in steady state and also in transient state. Details about the test rig utilized to validate the mathematical model are also discussed.

Paper accepted July, 2005. Technical Editor: Atila P. Silva Freire.

\section{Nomenclature}

$A_{A}=$ cylinder chamber $\mathrm{A}$ area, $\mathrm{m}^{2}$

$A_{B}=$ cylinder chamber $\mathrm{B}$ area, $\mathrm{m}^{2}$

$B_{c}=$ viscous friction coefficient, N.s $/ \mathrm{m}$

$C d=$ discharge coefficient, dimensionless

$f_{c}=$ cushioning factor, $\left(\mathrm{m}^{3} / \mathrm{s}\right) / \mathrm{Pa}^{1 / 2}$

$F_{a t}=$ friction force, $\mathrm{N}$

$K v=$ total flow coefficient, $\left(\mathrm{m}^{3} / \mathrm{s}\right) / \mathrm{Pa}^{1 / 2}$

$K v_{\exp A}=$ experimental partial flow coefficient for port A, $\left(\mathrm{m}^{3} / \mathrm{s}\right) / \mathrm{Pa}^{1 / 2}$

$K v_{\exp B}=$ experimental partial flow coefficient for port B, $\left(\mathrm{m}^{3} / \mathrm{s}\right) / \mathrm{Pa}^{1 / 2}$

$M_{p}=$ piston mass, $\mathrm{kg}$

$M_{t}=$ total mass, $\mathrm{kg}$

$p_{A}=$ pressure in cylinder chamber $\mathrm{A}, \mathrm{Pa}$

$p_{B}=$ pressure in cylinder chamber $\mathrm{B}, \mathrm{Pa}$

$p_{B e x}=$ cylinder pressure at port $\mathrm{B}, \mathrm{Pa}$

$p_{R}=$ reservoir pressure, $\mathrm{Pa}$

$p_{S}=$ supply pressure, $\mathrm{Pa}$

$q_{V}=$ volumetric flow rate, $\mathrm{m}^{3} / \mathrm{s}$

$q_{V A}=$ cylinder flow rate at port $\mathrm{A}, \mathrm{m}^{3} / \mathrm{s}$

$q_{V B}=$ cylinder flow rate at port $\mathrm{B}, \mathrm{m}^{3} / \mathrm{s}$

$v=$ speed, $\mathrm{m} / \mathrm{s}$

$V_{A}=$ chamber A volume, $\mathrm{m}^{3}$

$V_{B}=$ chamber B volume, $\mathrm{m}^{3}$

Greek Symbols

$\Delta p_{p}=$ valve partial pressure difference, $\mathrm{Pa}$

$\Delta p_{t}=$ valve total pressure difference, $\mathrm{Pa}$

$\Delta p_{c}=$ cushioning orifice pressure difference, $\mathrm{Pa}$

$\Delta p_{g}=$ global pressure difference, $\mathrm{Pa}$

$\beta_{e}=$ effective bulk modulus, $\mathrm{Pa}$

\section{Auto-Adjustable Stroke End Cushioning Device}

An asymmetric double action cylinder that uses auto-adjustable devices for the forward and return cushioning movements is shown in Fig. 1. This effect results from the cushioning tapered bush penetration into the outflow channel at the base and at the piston head of the cylinder. The passage of the hydraulic fluid through the narrow gap between the outflow channel and the cushioning bush increases the pressure in the corresponding chamber and, as a result, 
produces a force in the opposite direction of the movement, establishing a substantial reduction in the piston speed.

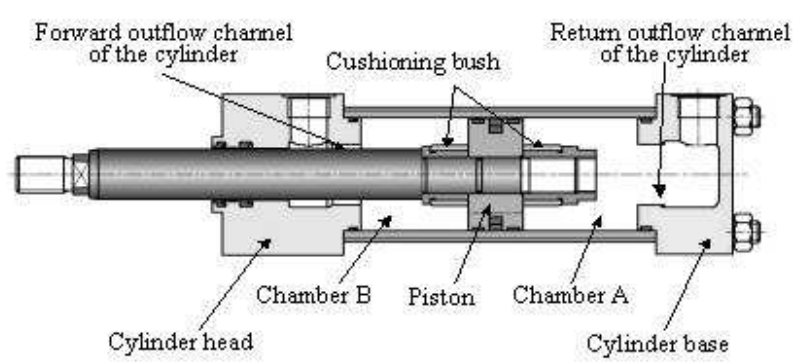

Figure 1. Hydraulic cylinder with auto-adjustable stroke end cushion (BOSCH REXROTH, 2000).

The parameters considered essential to size this auto-adjustable cushioning are: moving load, rod speed, assembly position and supply pressure.

In Fig. 2 a hydraulic cylinder with an auto-adjustable stroke end cushioning device and its main parts can be seen. In Fig. 3 the components of the cushioning device, including the two cushioning bushes are shown.

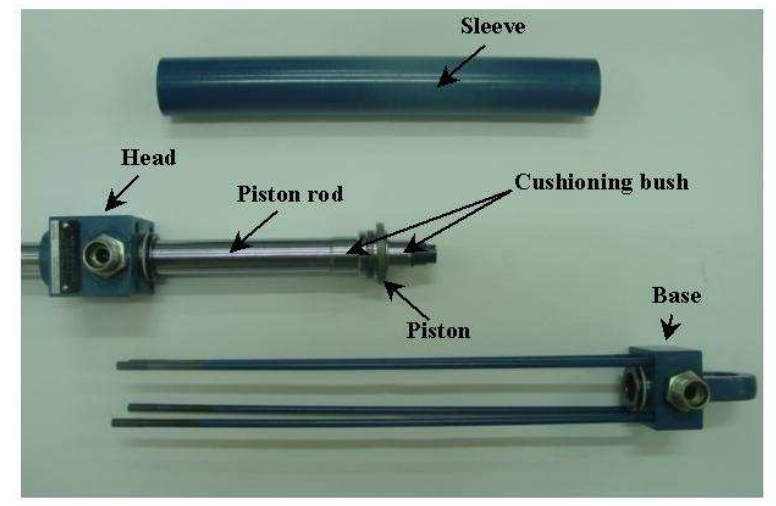

Figure 2. Parts of a hydraulic cylinder with auto-adjustable stroke end cushion (BOSCH REXROTH, 2000).

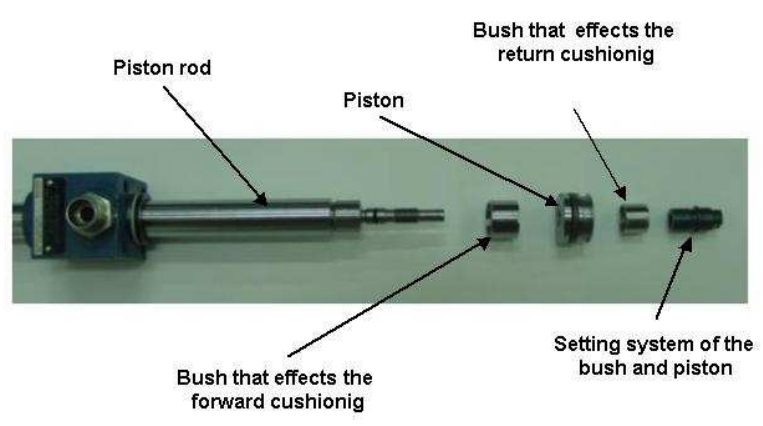

Figure 3. Cushioning device in parts (BOSCH REXROTH, 2000).

The fluid circulations during the cushioning moment and also at the beginning of the piston movement in the opposite direction are illustrated in Fig. 4. There are radial and axial gaps between the cushioning bush and the rod of the hydraulic cylinder, as shown in Fig 4 . When the bush initiates the cushioning effect, that is, when it penetrates into the outflow channel, the pressure rises inside the cushioning chamber (chamber B). The bush then moves in the axial direction toward the setting element. At this moment, the fluid has to cross the narrow transversal section formed between the cushioning bush and the external wall of the fluid outlet channel. Thereby the pressure in chamber B increases with the cushioning bush penetration into the cylinder head.

In Fig. 5 it can be observed that the cushioning bush has a variable external diameter along its length. Therefore, the pressure loss is not constant, its magnitude being defined by an increase or decrease in the external diameter of the cushioning bush. In the case of the studied cylinder, the length of the bush is $24.7 \mathrm{~mm}$ and the radial gap formed between the bush and channel varies between $0.04 \mu \mathrm{m}$ and $0.015 \mu \mathrm{m}$ along the length.

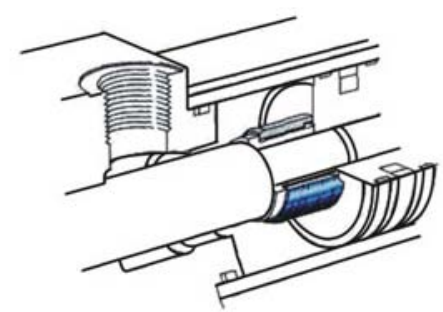

(a)

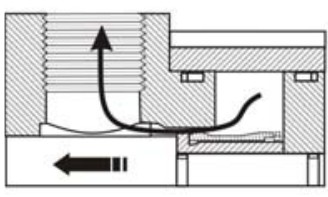

(b)

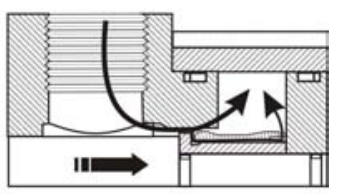

(c)
Figure 4. (a) Position of the bush on the piston rod; (b) Beginning of the cushioning effect; (c) Reverse movement without cushioning effect (MANNESMANN REXROTH, 1998).

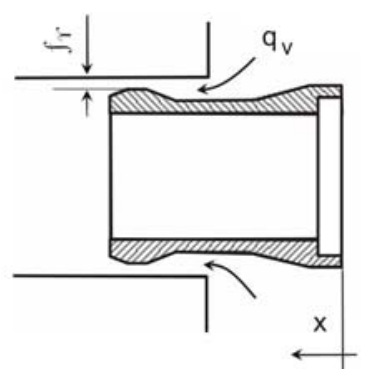

Figure 5. Geometric form of the cushioning bush studied (SCHWARTZ, 2004).

According to GUO (1996), the auto-adjustable device has the following advantages when compared to the conventional one: a) the auto-adjustable device has a smaller number of constructive parts, thereby reducing its manufacturing costs; b) an inappropriate setting of the adjustable restrictor valve in the conventional device may provoke excessive pressure peaks during the cushioning. On the other hand, the auto-adjustable device does not present this problem since there is no manual setting; c) due to the existence of an adjustable restrictor and a non-return valve, the conventional device may suffer leakage. Since the auto-adjustable device does not have valves, leakage is eliminated.

However, the auto-adjustable device suffers some disadvantages according to LIE et al (2000), such as: a) the cushioning pressure is directly dependent on the initial cylinder speed; b) generation of 
excessive cushioning pressures due to incorrect cushioning sizing, since the appropriate adjustment of the cushioning requires an understanding of transient behavior which is often not known by the user; c) the cushioning pressure is at a maximum at the onset of the cushioning and it decrease through the cushioning bush stroke, instead of maintaining an optimal cushioning effect.

\section{Test Rig}

The experimental work required the development of a test rig, which permitted the simulation of real loading situations. This rig is composed of an asymmetrical hydraulic cylinder with an autoadjustable stroke end cushioning device, a proportional directional valve and a set of loading weights. The test rig utilized is shown in Fig. 6, which is installed in the Laboratory of Hydraulic and Pneumatic Systems - LASHIP - Mechanical Engineering Department - UFSC.

The hydraulic circuit of the rig adheres to ISO 1219-1 (ISO, 1991) and ISO 1219-2 (ISO, 1995) and is presented in Fig. 7. The Hydraulic Power and Conditioning Unit (HPCU) possess two pumps of $8.33 \times 10^{-4} \mathrm{~m}^{3} / \mathrm{s}(50 \mathrm{~L} / \mathrm{min})$ each, being able to operate to a work pressure up to $21 \mathrm{MPa}$ (210 bar). Table 1 identifies the components of the circuit shown in Fig 7.

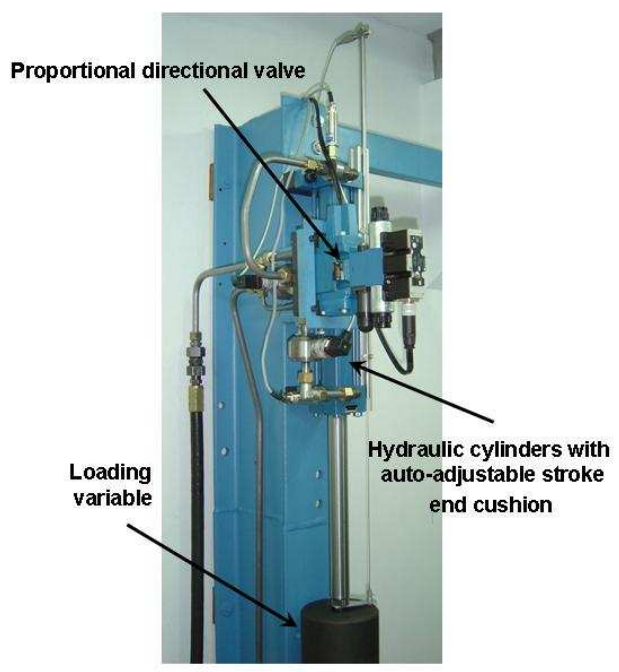

Figure 6. Test rig for auto-adjustable stroke end cushioning device installed at LASHIP/UFSC.

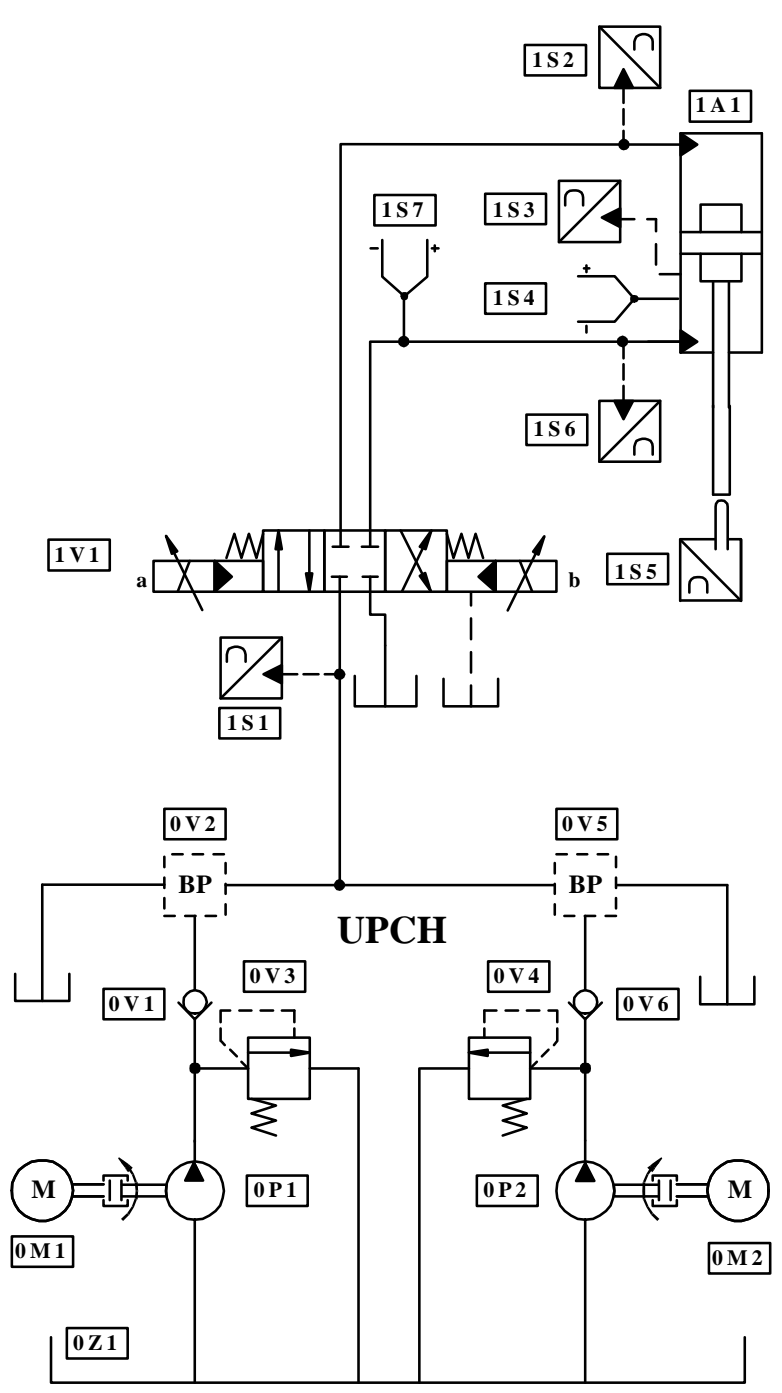

Figure 7. Hydraulic circuit used in the test rig.

Table 1. Identification of the hydraulic circuit components.

\begin{tabular}{|c|c|c|}
\hline Description & Circuit & Component \\
\hline Axial piston pumps & 0 & P1, P2 \\
\hline Non-return valve & 0 & V1, V6 \\
\hline Manifolds with proportional flow and pressure valves & 0 & V2, V5 \\
\hline Pressure relief valve & 0 & V3, V4 \\
\hline Electric motor & 0 & M1, M2 \\
\hline Reservoir & 0 & $\mathrm{Z1}$ \\
\hline Proportional directional valve - MANNESMANN REXROTH/4WRZ10E185-7X/ED3V & 1 & V1 \\
\hline Asymmetrical hydraulic cylinder - BOSCH REXROTH/ CDT3MS263/45/400Z1X/B1HHLM & 1 & $1 \mathrm{~A} 1$ \\
\hline Fe-Cu Ni Thermocouple & 1 & S7, S4 \\
\hline Pressure transmitter - measurement range 0 to 200 bar, measurement uncertainty \pm 0.4 bar & 1 & S1 \\
\hline Pressure transducer - measurement range 0 to 200 bar, measurement uncertainty \pm 0.18 bar & 1 & S2 \\
\hline Pressure transducer - measurement range 0 to 500 bar, measurement uncertainty \pm 0.18 bar. & 1 & S3 \\
\hline Pressure transmitter - measurement range 0 to 200 bar, measurement uncertainty \pm 0.4 bar & 1 & S6 \\
\hline Displacement transducer - measurement range -200 to $200 \mathrm{~mm}$, measurement uncertainty $\pm 0.23 \mathrm{~mm}$ & 1 & S5 \\
\hline
\end{tabular}


The flow rate and supply pressure are controlled by proportional valves in the manifolds 0V2 and 0V5 installed in the hydraulic power conditioning unit.

During the tests, the flow rate in the hydraulic cylinder is controlled by a proportional directional valve $1 \mathrm{~V} 1$, where the pressure and displacement are measured through the transducers shown in Fig 7. The fluid employed is a mineral oil ISO VG 32, with viscosity $32 \times 10^{-6} \mathrm{~m}^{2} / \mathrm{s}$ (32 Cst) and mass density $842 \mathrm{~kg} / \mathrm{m}^{3}$ at $40{ }^{\circ} \mathrm{C}$. The working temperature is maintained at $40{ }^{\circ} \mathrm{C} \pm 2{ }^{\circ} \mathrm{C}$ through a fluid temperature control system.

The test rig loading is achieved through five steel blocks with $17.8 \mathrm{~kg}$ each. These blocks are mounted one by one on the hydraulic cylinder rod, and the load range is $0 \mathrm{~kg}$ to $89 \mathrm{~kg}$.

The electrical circuit for signal acquisition shown in Fig. 8 is utilized to determine static and dynamic characteristics of the system. Pressure and displacement transducer signals receive appropriate treatment in a signal conditioner and are stored in a microcomputer through the data acquisition system AQX (REIVAX, 2001), which is capable of operating up to $16 \mathrm{~A} / \mathrm{D}$ channels.

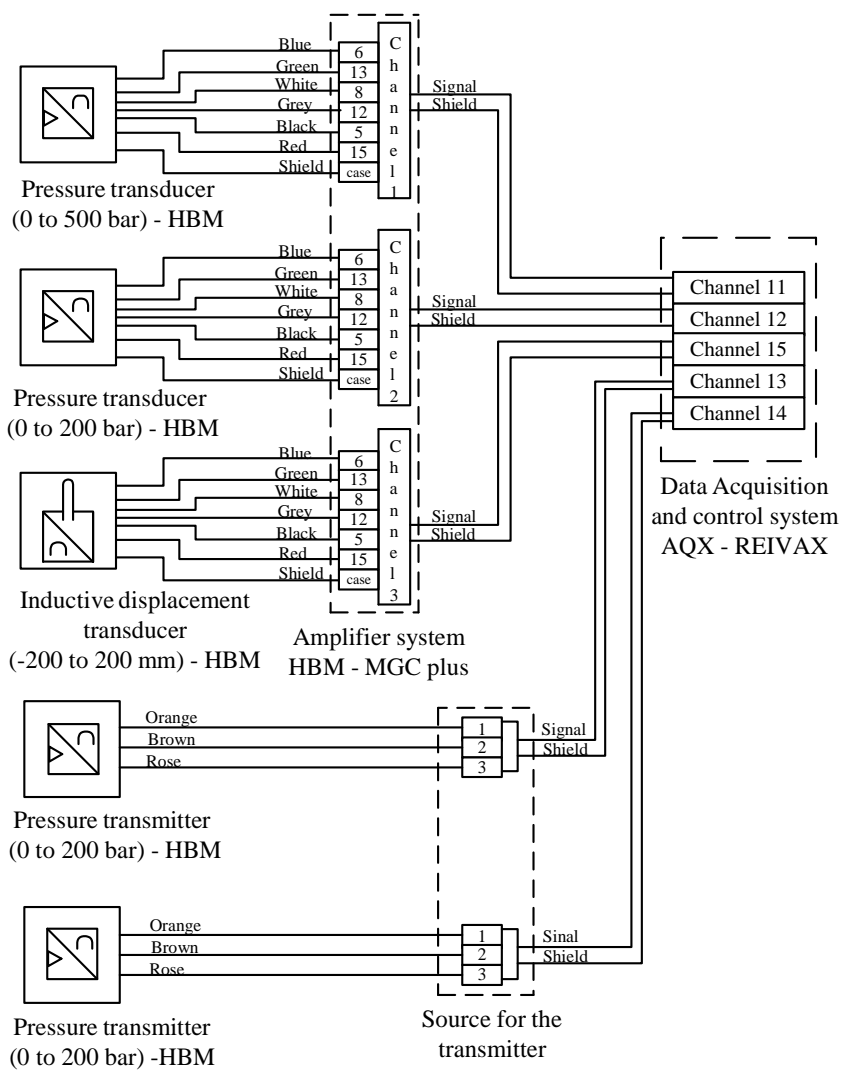

Figure 8. Electrical circuit for signal acquisition.

\section{Mathematical Modeling}

To the nonlinear modeling, fluid mechanics and classic mechanics equations were applied, specifically the mass conservation law and conservation of energy to the fluid flow and Newton's second law of motion to the piston and loading. (LINSINGEN, 2001; DE NEGRI, 1987).

In Fig. 9 an illustrative drawing of the interconnection between the valve and cylinder is shown. The valve commands the cylinder through its main stage, which in turn is commanded by the pilot stage. In the upper part of the drawing the electronic circuit that controls the solenoids in response to an external reference signal is shown. The main variables of the equations used to model the valve and hydraulic cylinder are also shown in Fig. 9.

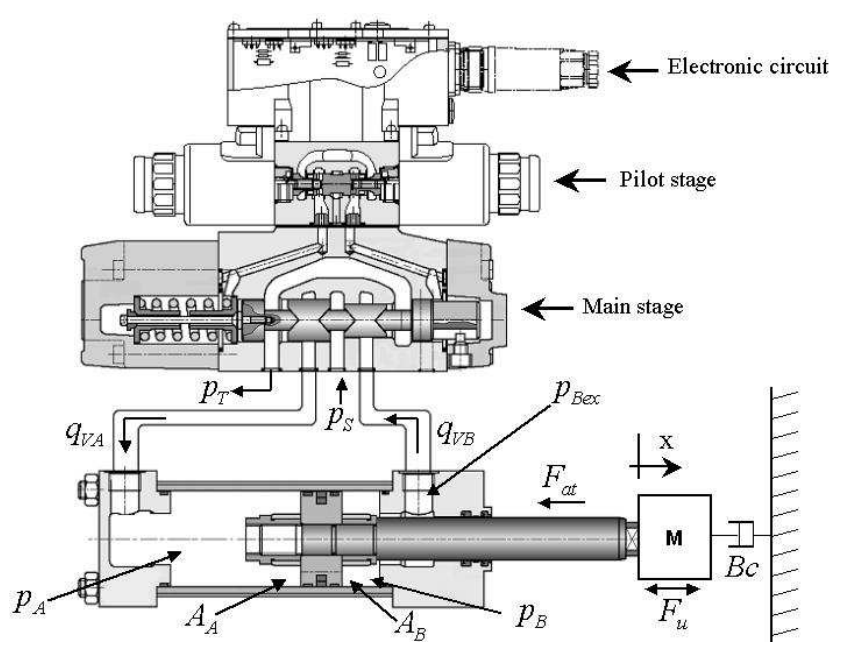

Figure 9. Main Hydraulic components of the test rig.

\section{Proportional Directional Valve}

The mathematical description of the behavior of the asymmetrical proportional directional 4-way valve can be obtained from Bernoulli's equation (FOX and McDONALD, 1995) applied to each one of the control orifices $(3,4,5$ and 6$)$ identified in Fig. 10. As represented in equations (1) and (2), each control orifice is under the effects of the pressure differences between two specific ports of the valve.

$$
\begin{aligned}
q_{V A} & =C d \cdot A_{3} \cdot \sqrt{\frac{2}{\rho} \cdot\left(p_{S}-p_{A}\right)}-C d \cdot A_{4} \cdot \sqrt{\frac{2}{\rho} \cdot\left(p_{A}-p_{R}\right)} \\
q_{V B} & =C d \cdot A_{6} \cdot \sqrt{\frac{2}{\rho} \cdot\left(p_{S}-p_{B}\right)}-C d \cdot A_{5} \cdot \sqrt{\frac{2}{\rho} \cdot\left(p_{B}-p_{R}\right)}
\end{aligned}
$$

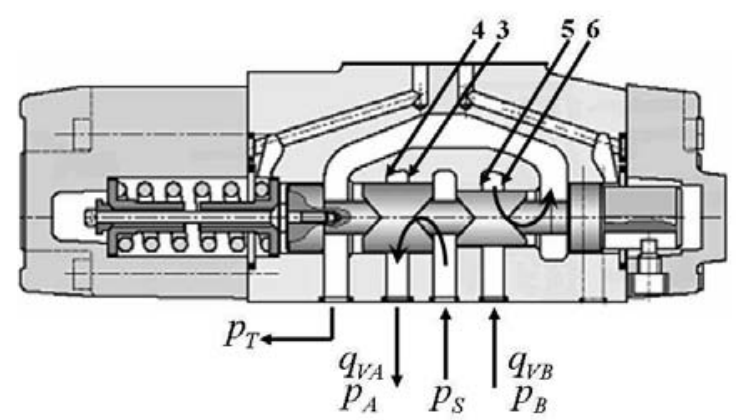

Figure 10. Representation the main stage of the directional four-way valve.

According to FURST (2001), a challenge faced by the hydraulic systems designer during the sizing stage is to obtain from the manufacturer's catalogue the correct values for the required parameters. The lack of standardization among manufacturers in characterizing products is the main reason for this difficulty. Another factor is the great differences between industrial practices and proper mathematical treatment of the dynamic analysis of 
systems since the product specifications do not consider their use in dynamic equations.

As a common treatment applied to valves with a critical or supercritical center, the equations for the flow through ports $\mathrm{A}$ and $B$ are described with only one of the above terms, since one of the two control orifices ( 3 or 4 and 5 or 6 ), will always be practically blocked due to the overlapping between the spool and the body of the valve (MERRITT, 1967; DE NEGRI, 2001). Therefore, using the total flow coefficient $K_{v}$ defined in FURST (2001), the flow through the working ports A and B can be expressed as:

$$
\begin{gathered}
q_{V A}=K v \cdot \frac{U}{U_{n}} \cdot \sqrt{\Delta p_{t}} \\
q_{V B}=K v \cdot \frac{U}{2 U_{n}} \cdot \sqrt{\Delta p_{t}}
\end{gathered}
$$

The total flow coefficient is easily obtained from valve manufacturer's catalogues, since it corresponds to the ratio between the flow through port $\mathrm{A}$ and the square root of a chosen total pressure drop (between port $\mathrm{S}$ and $\mathrm{T}$ ) when a nominal command is applied as the spool displacement $\left(\mathrm{x}_{\mathrm{n}}\right)$, current $\left(i_{n}\right)$ or voltage $\left(U_{n}\right)$ (FURST, 2001). Figure 11 shows the flow curve versus relative valve opening used in the present study as it appears in the catalogue (MANNESMANN REXROTH, 1996). The adoption of a constant value coefficient for the flow calculation corresponds to the linearization of curve 1 shown in Fig. 11, establishing a straight line that passes through both coordinates $(0 \%, 0 \mathrm{~L} / \mathrm{min})$ and $(100 \%, 85$ $\mathrm{L} / \mathrm{min}$ ).

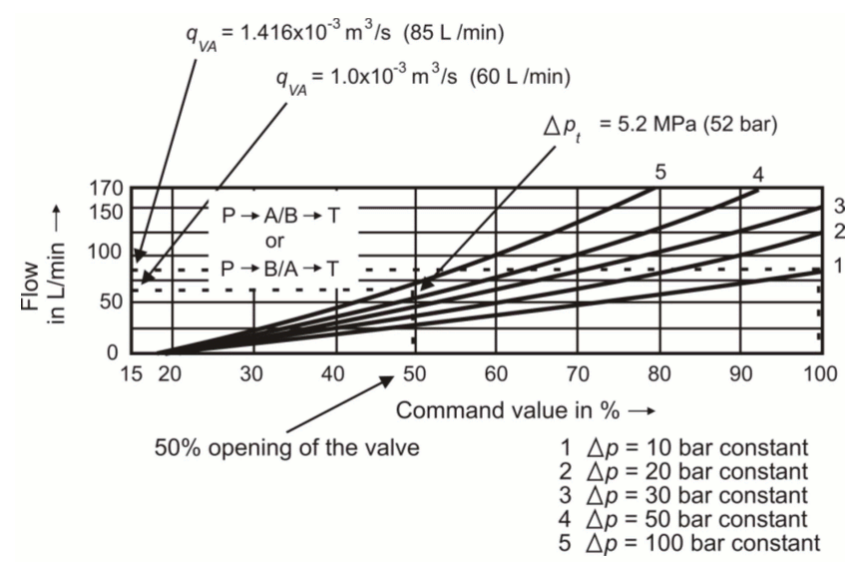

Figure 11. Characteristic flow curves of the proportional directional valve (MANNESMANN REXROTH, 1996).

The use of equations (3) and (4) with constant coefficients is suitable for the analysis and design of electro-hydraulic systems for position control and trajectory tracking, as seen in CUNHA et al. (2002), LI (2001); SOHL and BOBROW (1999). However, since in this study the focus is the detailed characterization of an internal element of the cylinder, the flow coefficient cannot be treated as a term independent of the operational conditions to which the cylinder, and consequently, the valve, are submitted. Thus, equations (3) and (4) assume the form of equations (5) and (6), where the experimental partial flow coefficients defined reflect the real behavior of the valve for the conditions under which the cushioning device tests are carried out.

$$
q_{V A}=K v_{\exp A} \cdot \sqrt{\Delta p_{p}}
$$

$$
q_{V B}=K v_{\exp B} \cdot \sqrt{\Delta p_{p}}
$$

In Fig. 12, the behavior of the partial flow coefficients during the forward movement of the hydraulic cylinder is presented. The coefficient $K v_{\exp A}$ is calculated dividing the real flow by the square root of the pressure drop between the working and supply ports ( $\mathrm{S}$ $\rightarrow \mathrm{A}$ ); In turn, $K v_{\exp B}$ results from the division of the real flow by the pressure drop between working port $\mathrm{B}$ and return port $\mathrm{T}(\mathrm{B} \rightarrow$ $\mathrm{T})$. In this same figure, the significant variation of these coefficients can be observed at the departure of the cylinder, the moment when it leaves the cushioning region, as well as at the moment when the cylinder reaches the cushioning region at the stroke end of the forward movement.

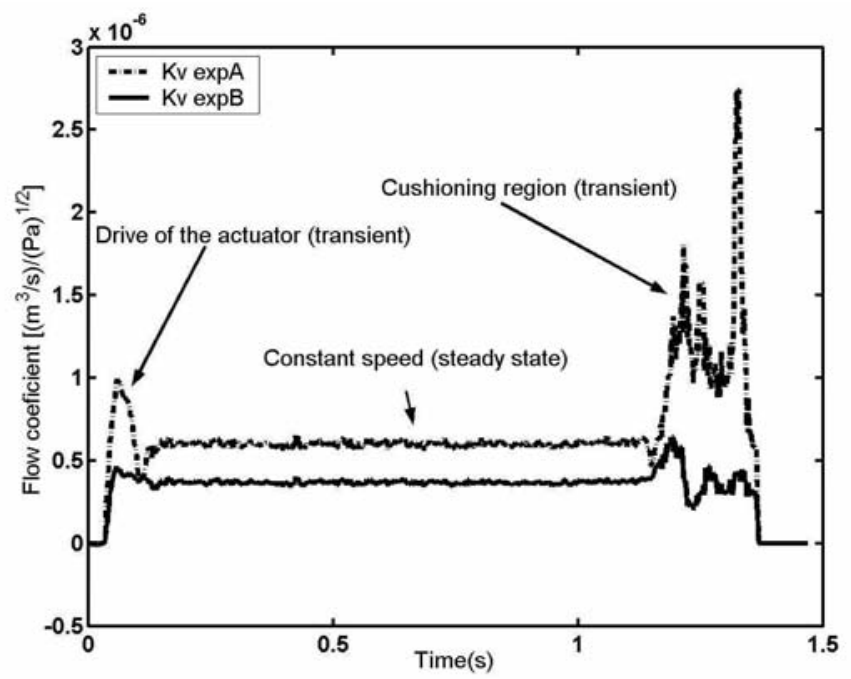

Figure 12. Behavior of the coefficients $k v_{\exp A}$ and $K v_{\text {expB }}$ with supply pressure of $4.1 \mathrm{MPa}$ and $50 \%$ valve opening.

In the region where the piston displacement occurs with constant speed, associated with a 50\% valve opening, the corresponding flow coefficient can be calculated by equation (7) giving the value of $4.38 \times 10^{-7} \mathrm{~m}^{3} /\left(\mathrm{s} \cdot \mathrm{Pa}{ }^{1 / 2}\right)$.

$$
K v=K v_{\exp A} / \sqrt{2}
$$

During the steady state condition the total pressure drop in the valve was 5.2 $\mathrm{MPa}$ (52 bar) and the corresponding flow rate can be calculated through equation 3 , giving the value of $1 \times 10^{-3} \mathrm{~m}^{3} / \mathrm{s}(60$ $\mathrm{L} / \mathrm{min}$ ). This flow rate can be obtained from Fig. 10, which also corresponds to the steady state condition, demonstrating the validity of the experimental data.

Thus, the data are appropriate for the mathematical model validation of the valve-cylinder system, permitting the analysis of its behavior and, consequently, the effect of the auto-adjustable stroke end cushioning device. It is important to emphasize that these experimental partial flow coefficients are valid for the conditions under which they were determined. In this study they are is valid therefore for a valve opening of $50 \%$.

\section{Hydraulic Cylinder}

As seen in Fig. 9, the main forces acting on the cylinder are: inertia force resulting from the acceleration of the mass, forces due to the pressures operating at each side of the piston and friction 
forces. Consequently, the movement equation for the piston can be written as:

$$
\left(p_{A} \cdot A_{A}\right)-\left(p_{B} \cdot A_{B}\right)=M_{t} \cdot \frac{d^{2} x}{d t^{2}}+B c \cdot \frac{d x}{d t}+F_{a t}
$$

In turn, the application of the mass conservation equation for the defined control volume inside each chamber, determines that the inflow subtracted from the outflow of each chamber equals the variation rate of the volume over time added to the term corresponding to the expansion or compression of the fluid at this control volume (MERRITT, 1967; DE NEGRI, 2001). Therefore:

$$
\begin{aligned}
& q_{V A}=A_{A} \frac{d x}{d t}+\frac{V_{A}}{\beta e} \cdot \frac{d p_{A}}{d t} \\
& q_{V B}=A_{B} \frac{d x}{d t}-\frac{V_{B}}{\beta e} \cdot \frac{d p_{B}}{d t}
\end{aligned}
$$

\section{Cushioning Device: Experimental Modeling}

Considering that the cushioning device essentially provides a restriction to the fluid flow and assuming a quadratic relation between the flow and the pressure difference, this behavior is represented in the following expression:

$$
q_{V B}=f_{c} \sqrt{\Delta p_{c}}
$$

In Equation 11 the cushioning factor $f_{c}$ is defined, which is dependent on the geometric form of the passage section between the cushioning bush and the channel at the cylinder base or head and, consequently, on the flow conditions established by the piston movement. The adoption of this cushioning factor aims to overcome the difficulty identified by the authors, through theoreticalexperimental comparisons, of using models of flow through orifices or idealized ducts described in the fluid mechanics literature (FOX and McDONALD, 1995). This difficulty arises because the passage section has an extremely variable geometry (SCHWARTZ, 2004) as can be seen in Fig. 4 and Fig. 9.

The small amount of researches related to the cushioning in hydraulic cylinders has caused difficulties in obtaining results by other researchers for equivalent situations. Through an exhaustive search for similar studies, including the publications of the main research centers in hydraulic and pneumatic technology such as IHT- Institute of Hydraulics and Automation - Finland, IFAS Institut Für Fluidtechnische Antriebe und Steverungen IFAS Germany and Center for Power Transmission and Motion Control United Kingdom, it was possible to identify only the study presented by LIE et al (2000). However, LIE et al (2000) use the problem approach of the laminar flow between a fixed plane plate and another one in movement. This problem approach was not found to be appropriated to model the real system discussed in this paper.

The cushioning factor $f_{c}$ is calculated according to Equation (11) using experimental data on a flow through the passage section and the corresponding pressure drop (SCHWARTZ, 2004).

In Fig. 12 and Fig. 13 the variation of this factor with cylinder displacement is presented. In these figures six tests are presented, each carried out with an $89 \mathrm{~kg}$ load and different operation conditions, as indicated in Table 2.

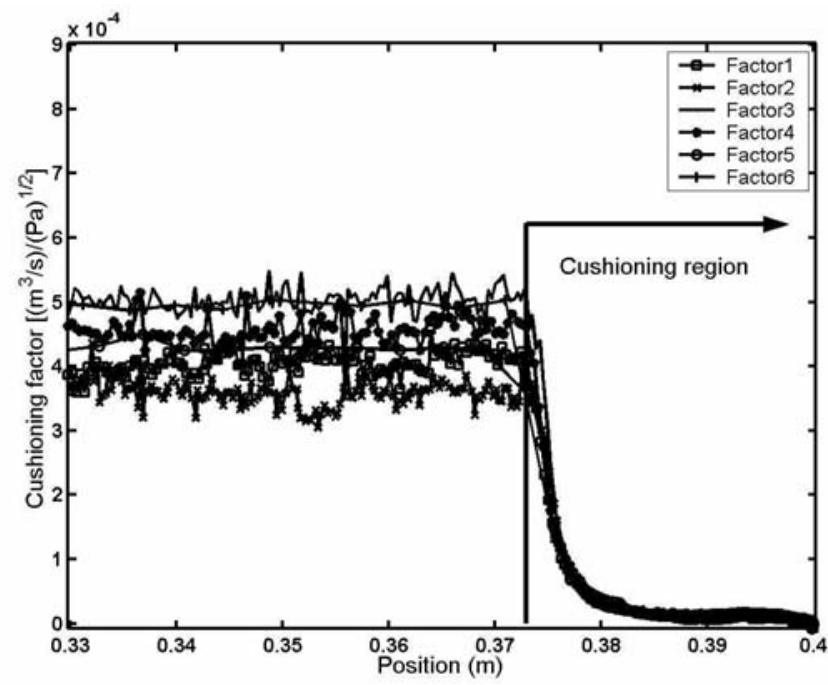

Figure 13. Behavior of the cushioning factor as a function of the position under different working conditions (see Table 2).

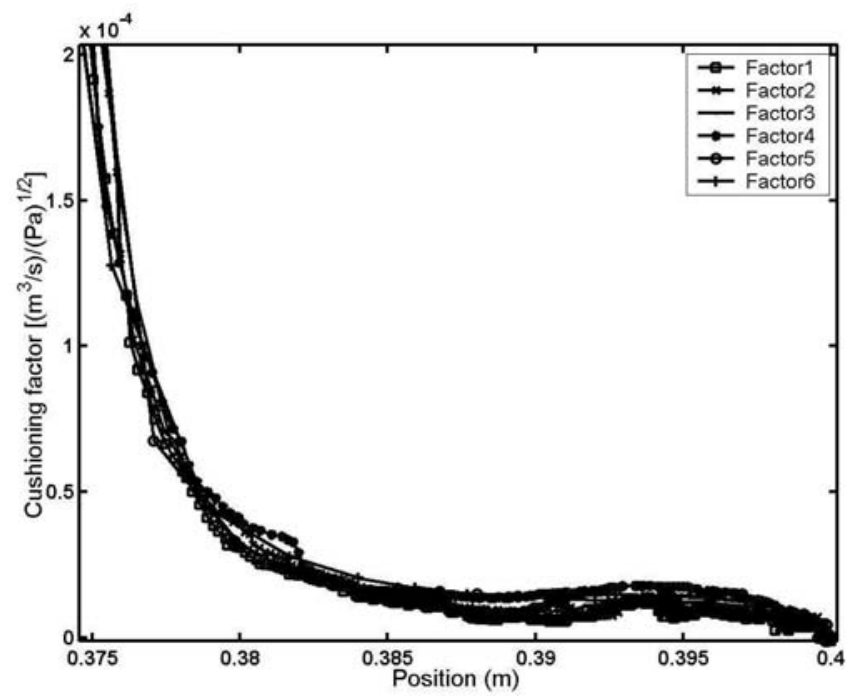

Figure 14. Enlarged view of the cushioning region of the graph given in Fig. 12.

Table 2. Parameters used in the experiments relating to Fig. 12 and Fig. 13.

\begin{tabular}{|c|c|c|c|}
\hline \multicolumn{4}{|c|}{ Test parameters } \\
\hline Factor & $\mathbf{p}_{\mathbf{S}}(\mathbf{P a})$ & $\mathbf{v}(\mathbf{m} / \mathbf{s})$ & Load $(\mathbf{k g})$ \\
\hline 1 & $3 \mathrm{MPa}$ & $0.36 \mathrm{~m} / \mathrm{s}$ & $89 \mathrm{~kg}$ \\
\hline 2 & $4 \mathrm{MPa}$ & $0.28 \mathrm{~m} / \mathrm{s}$ & $89 \mathrm{~kg}$ \\
\hline 3 & $5 \mathrm{Mpa}$ & $0.33 \mathrm{~m} / \mathrm{s}$ & $89 \mathrm{~kg}$ \\
\hline 4 & $8 \mathrm{MPa}$ & $0.38 \mathrm{~m} / \mathrm{s}$ & $89 \mathrm{~kg}$ \\
\hline 5 & $10 \mathrm{MPa}$ & $0.40 \mathrm{~m} / \mathrm{s}$ & $89 \mathrm{~kg}$ \\
\hline 6 & $15 \mathrm{MPa}$ & $0.45 \mathrm{~m} / \mathrm{s}$ & $89 \mathrm{~kg}$ \\
\hline
\end{tabular}

In Fig. 14 and Fig. 15 five tests are presented, where each was carried out with different loads from zero external mass (only the piston mass) up to total available mass, with supply pressure maintained at $4.1 \mathrm{MPa}(41 \mathrm{bar})$ and piston speed at $0.35 \mathrm{~m} / \mathrm{s}$ for all tests. 


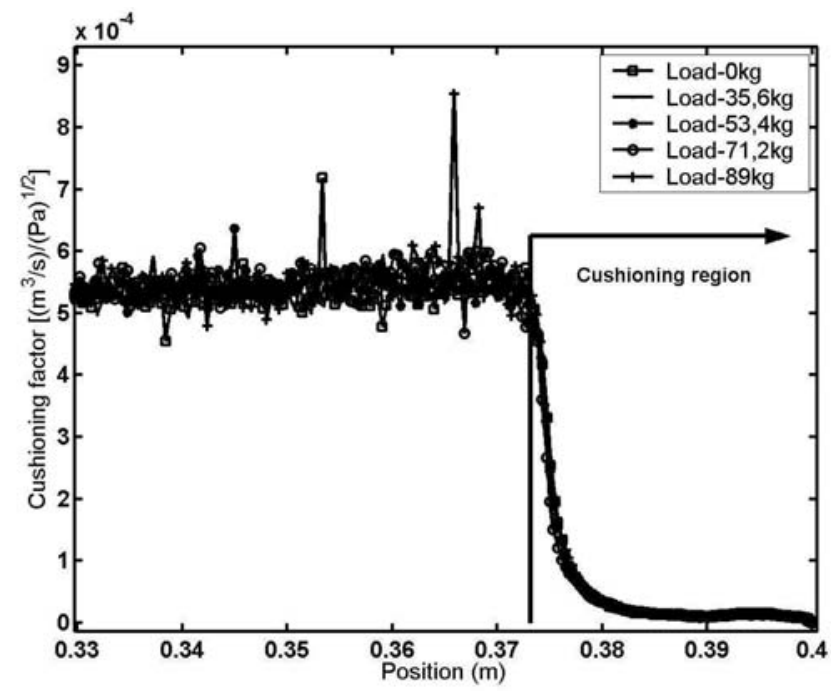

Figure 15. Behavior of the cushioning factors as a function of the position, for different loads.

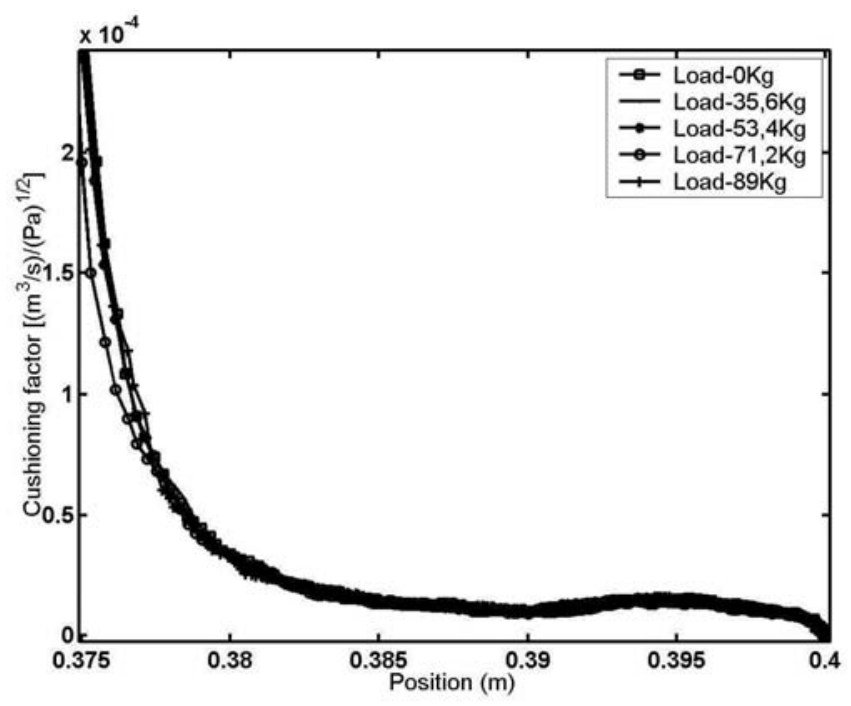

Figure 16. Enlarged view of the cushioning region of the graph given in Fig. 14.

Through these tests it can be evidenced that the behavior of the cushioning factor, at the moment that the piston reaches the cushioning region, is not influenced by the working conditions of the hydraulic cylinder. Thus, one concludes that the cushioning is only related to the geometry of the cushioning bush (SCHWARTZ, 2004).

The greatest dispersion among test results occurs before the cushioning bush initiates the penetration at the channel, when the cushioning device does not affect the real behavior of the cylinder and, consequently, the cushioning factor calculated does not influence the simulation results. In the region where the effect of the cushioning factor is significant, the maximum dispersion of the results is $\pm 6 \times 10^{-6} \mathrm{~m}^{3} / \mathrm{s} /(\mathrm{Pa})^{1 / 2}$.

To make the mathematical model consistent, the combined effect of pressure loss in the orifice of the valve $(B \rightarrow T)$ and in the cushioning orifice is considered. It follows that:

$$
\Delta p_{g}=\Delta p_{p}+\Delta p_{c}
$$

Substituting equations (6) and (11) in (12), the expression of the flow that leaves chamber $B$ is obtained, overriding equation 6 :

$$
q_{V B}=K v_{\exp B} \cdot f_{c} \cdot \sqrt{\frac{\Delta p_{g}}{f_{c}^{2}+\left(K v_{\exp B}\right)^{2}}}
$$

\section{Theoretical-Experimental Results}

\section{Parameters of the System}

The mass $M_{p}$ and the piston areas $\left(A_{A}\right.$ e $\left.A_{B}\right)$ were experimentally determined for the hydraulic cylinder. The volumes of oil $\left(V_{A}\right.$ e $\left.V_{B}\right)$ include the internal volume of the chambers of the cylinder and the tubes up to the valve.

As previously seen, $K v_{\exp A}$ and $K v_{\exp B}$ having been experimentally determined for a valve opening of $50 \%$ gives an accurate relation between the flow and the pressure drop.

Another experimentally determined parameter was the hydraulic cylinder friction (MACHADO, 2003), whose graph is shown in Fig. 16. The friction graph was obtained with the hydraulic cylinder placed in a horizontal position. Applying a constant voltage in the proportional valve, a difference of pressure is created that provokes the movement with constant speed. As in this condition of steady state there is no external force applied to the cylinder, the force originating from the pressure difference corresponds to the total friction force.

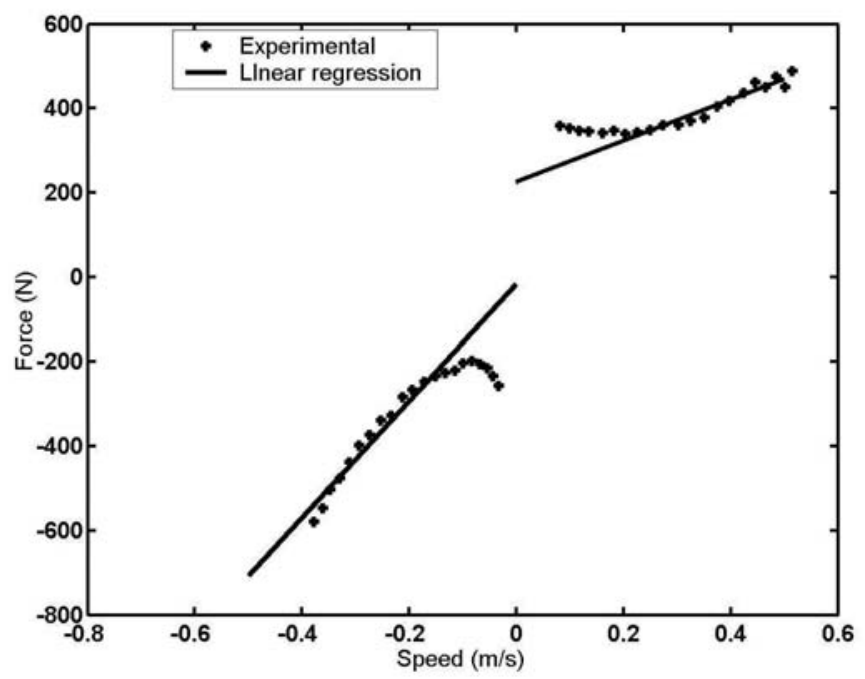

Figure 17. Friction graph of the hydraulic cylinder.

Supply pressure $p_{S}$ is another parameter to be observed. In Fig. 17 considerable variation of the supply pressure is identified, as much at the departure of the cylinder, as at the moment it reaches the cushioning. Since the pressures are interdependent, the impossibility of keeping the supply pressure constant makes the pressures in the chambers of the cylinder fluctuate in a similar way. Thus, the operational conditions are modified and the cushioning capacity of the auto-adjustable device is reduced.

This latter fact can be understood considering that the sizing of cushioning devices in hydraulic cylinders uses the supply pressure as a parameter. Pressure variations during cylinder operation will modify the damping capacity of the cylinder since it will be operating under different conditions to whose under which it was sized. 
The oscillations in supply pressure that occur at the beginning of the cylinder movement and at the moment that the cushioning effect starts resulting from a high response time of the relief valves $0 \mathrm{~V} 3$ and 0V4 (Fig 7). In turn, it is possible to observe in Fig. 17 that the supply pressure is regulated at $5 \mathrm{MPa}(50 \mathrm{bar})$ when there is no flow through the cylinder, that is, at the beginning and at the stroke end of the piston. During the displacement at constant speed, a 20\% reduction in this pressure occurs due to the steady state errors of the valves. These operational errors are typical of relief valves and can be improved by employing an accumulator.

In order to validate the theoretical model, experimental supply pressure was used as an input parameter for the mathematical model.

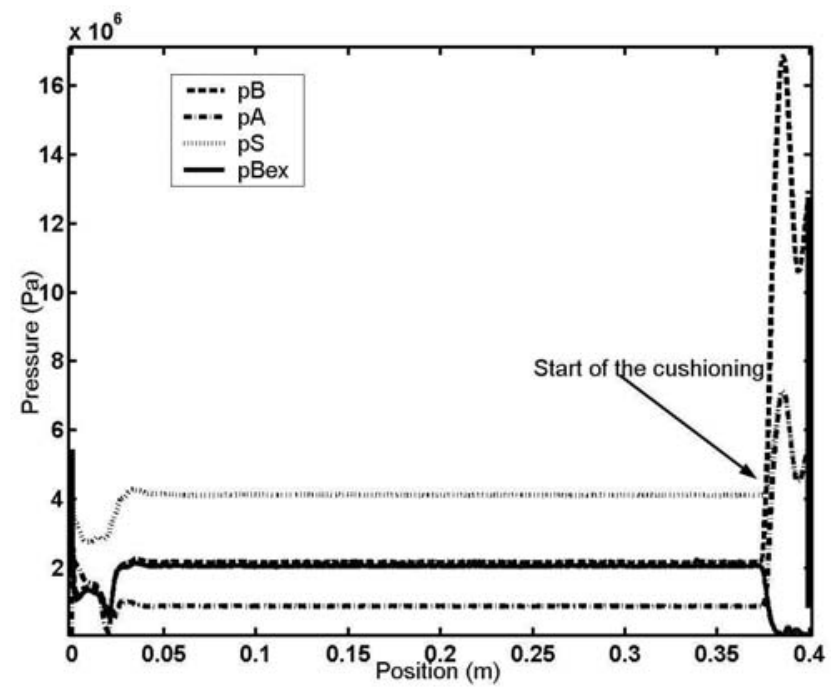

Figure 18. Pressures in the hydraulic cylinder chambers.

\section{Analysis With the Original Cushioning Device}

Firstly, system behavior results utilizing experimental values for the supply pressure, the flow coefficients of the valve and cushioning factor will be presented aiming to validate the mathematical model.

Through resources available in the software used for simulation, it was possible to employ the experimental values obtained with the test rig, presented in Fig. 6, as parameters of input in the model. Specifically, through the data and acquisition system AQX (REIVAX, 2001), one gets vectors with the dynamic behavior of these variables, with a sampling time of $1 \mathrm{~ms}$. Adjusting the same sampling time in the simulation software, a synchronism between the experimental parameters and the simulated ones was obtained.

In Fig. 18 the pressure behaviors in the hydraulic cylinder chambers as a function of time can be observed. Here the pressure behaviors are synchronized, that is, both experimental and simulated pressures increase at the point when the cylinder achieves the cushioning effect.

In Fig. 19, the behaviors of the simulated and experimental pressures against the piston displacement are shown. Since the supply pressure, the flow coefficient of the valve and the cushioning factor are experimental data, one can observe that the dynamic model employed describes satisfactorily the behavior of the pressures in the hydraulic cylinder chambers. The results obtained have a maximum error of $10 \%$, being consistent with those previously reported for theoretical-experimental studies in the hydraulic field as, for example, in SOHL and BOBROW (1999) and MATTILA and VIRVALO (2000).

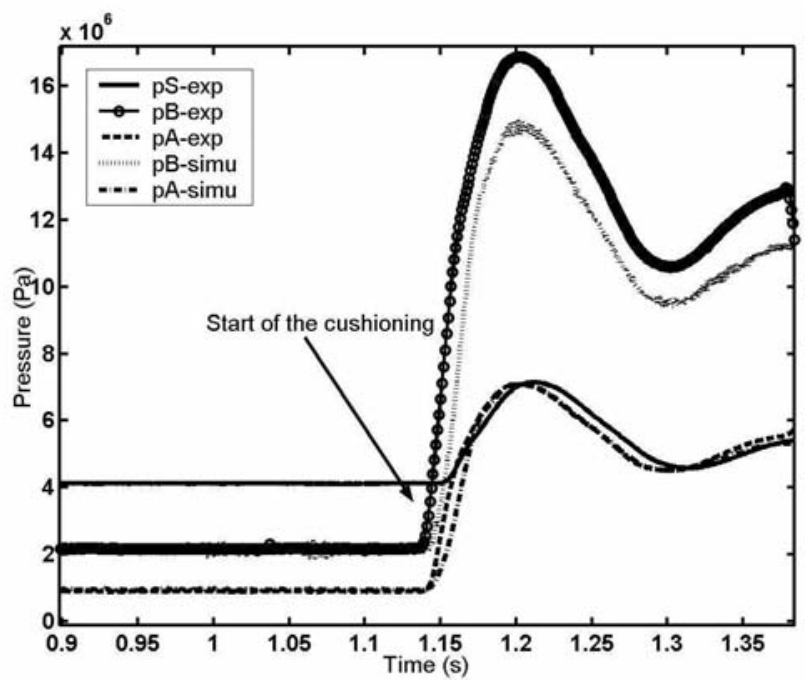

Figure 19. Pressures in the hydraulic cylinder chambers as a function of time.

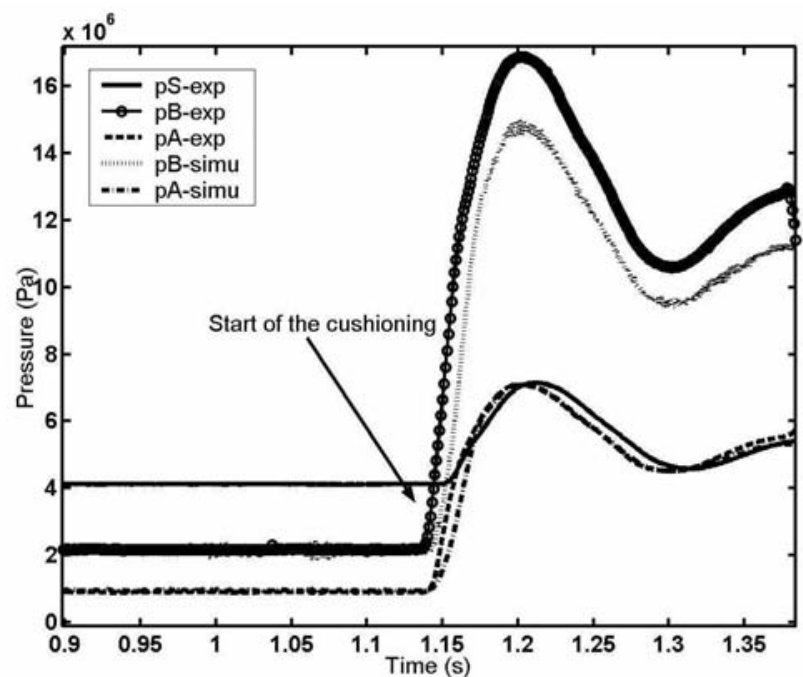

Figure 20. Pressures in the hydraulic cylinder chambers as a function of piston displacement.

The behavior of the cylinder speed against the displacement is presented in Fig. 20. For both the experimental and simulated results, the speed presents a non linear drop with displacement due to the irregular surface profile of the cushioning bush in the axial direction. This explains the high pressure peak at the beginning of the cushioning effect seen in Fig. 19. A new reduction of the orifice occurs when the piston is near of the stroke end, provoking a pressure increasing and, consequently, reducing the speed again. Analyzing these results, one can observe that the theoretical model describes the dynamic behaviors in full agreement with the experimental results.

Based on the results presented in Fig. 19 and Fig. 20, the validity of the mathematical model that describes the behavior of the valve-hydraulic cylinder system is proved. Consequently, it can be used in the characterization and sizing of the cushioning device. 


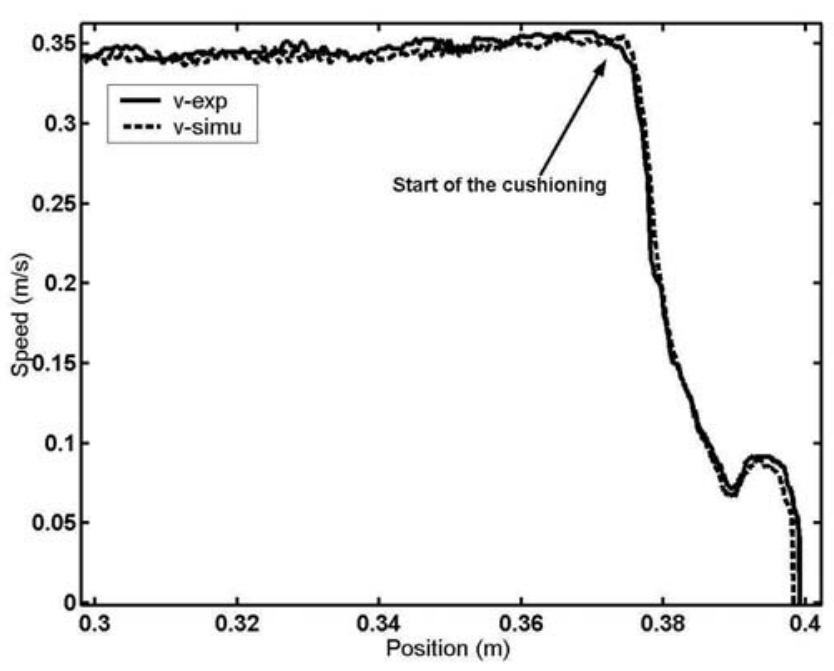

Figure 21. Theoretical-experimental speed, using the experimental cushioning factor and supply pressure.

The comparison between the experimental and theoretical cushioning factors created through a sequence of linear equations as a function of the position of the hydraulic cylinder is shown Fig. 21. Using this theoretical factor a comparison was made between the simulated and experimental speeds as shown in Fig. 22. This demonstrated the validity of the developed model that uses a mathematically expressed cushioning factor, which can be modified in subsequent studies.

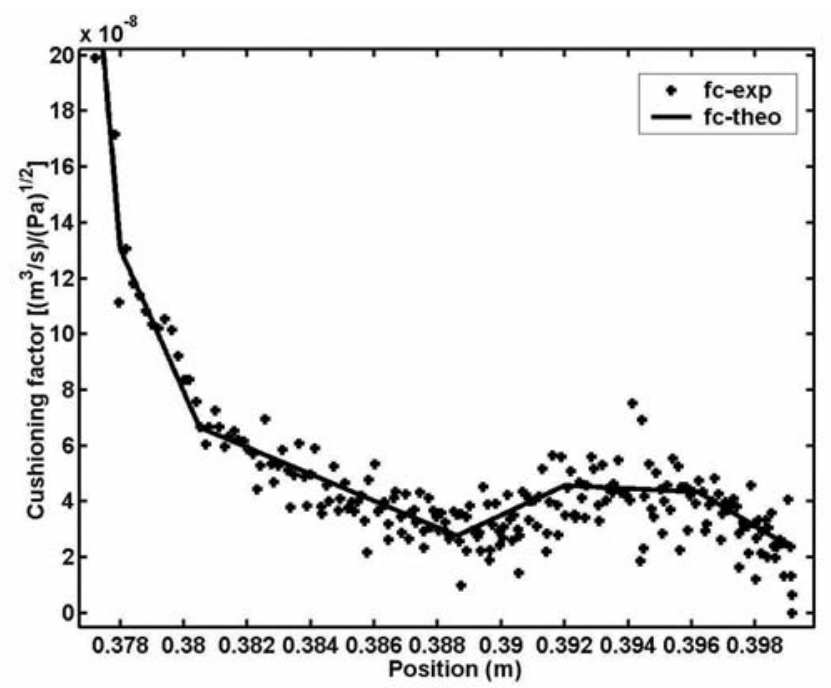

Figure 22. Comparison between the experimental and theoretical cushioning factors.

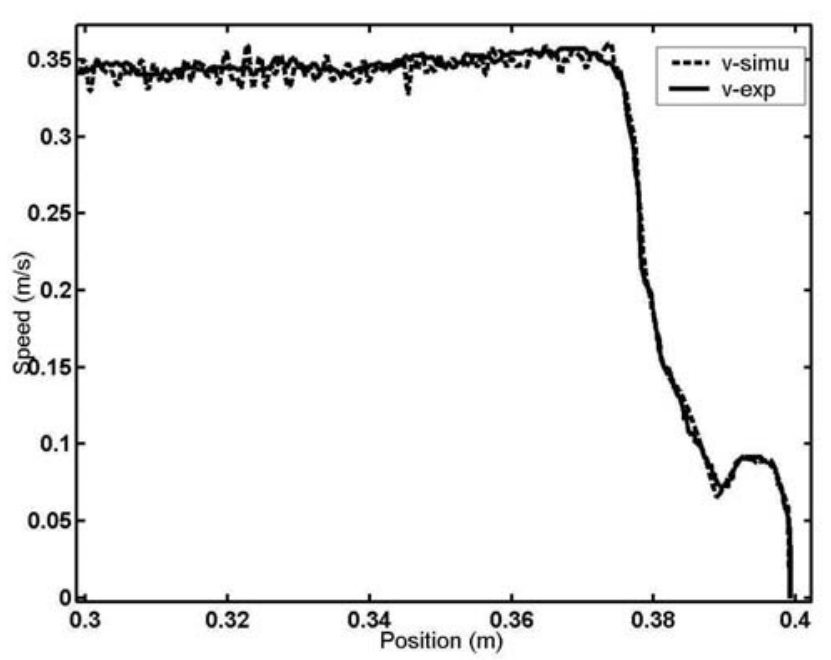

Figure 23. Comparison between the experimental and simulated speeds using a theoretical cushioning factor.

\section{Design of Cushioning Devices}

A validated mathematical model is an important tool in the design of dynamic systems. In the present discussion this will be used in the design of new cushioning devices, suitable for operational and loading conditions for which this device has not been capable of promoting the deceleration desired.

As operational situations distinct from those experimentally measured will be analyzed, firstly the experimental values for the supply pressure and the flow coefficients of the valve were substitute for constant values, obtaining, for example, the results shown in Fig. 23 where $p_{S}=4.1 \mathrm{MPa}$ (41 bar), $K v_{\text {expA }}=6 \times 10^{-7}$ $\mathrm{m}^{3} / \mathrm{s} /(\mathrm{Pa})^{1 / 2}$ e $K v_{\exp B}=3.7 \times 10^{-7} \mathrm{~m}^{3} / \mathrm{s} /(\mathrm{Pa})^{1 / 2}$. The lack of oscillation in the supply pressure reduces the pressure peak in chamber B from around $15 \mathrm{MPa}(150 \mathrm{bar})$ as seen in Fig. 19 to around $9 \mathrm{MPa}(90$ bar). From this brief analysis the effect that the variations in supply pressure in real hydraulic circuits have on the internal pressures of the circuit is clear. It is therefore possible to reach pressures higher than those of the maximum working conditions for which the component was manufactured.

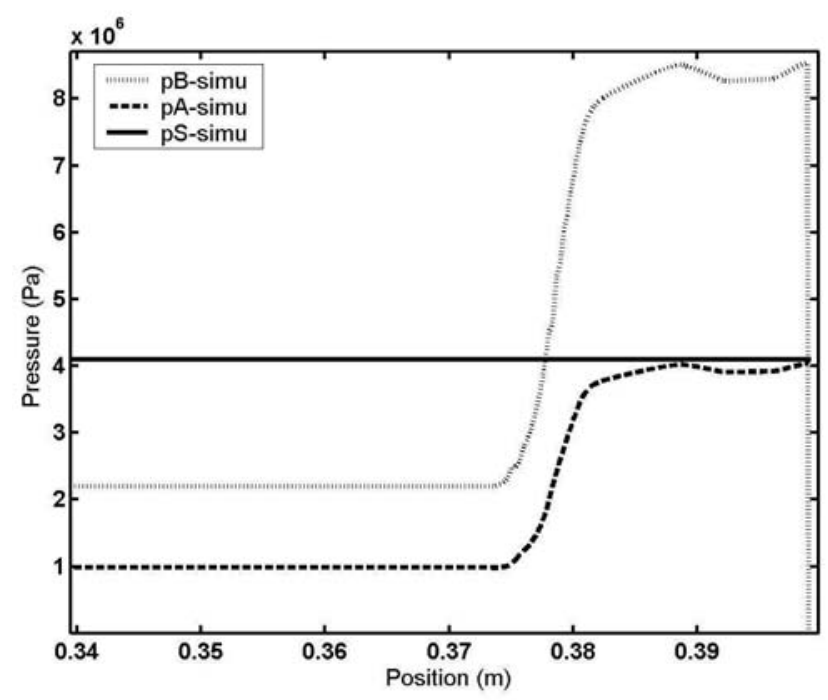

Figure 24. Cylinder chamber pressures with constant supply pressure. 
In Fig. 24 some cushioning pressure curves, obtained by GUO (2002) for the cushioning bush investigated in this work are presented. Curve 1 shows an ideal behavior and the other curves correspond to real situations. In situations 2 and 3 the same speed was employed, whereas cushioning sizing varied as did the cushioning bush surface profiles. Curve 4 describes a cushioning pressure for a lower speed compared to that of other curves. Comparing Fig. 23 that describes the behavior of the pressure in chamber B using constant supply pressure, with pressure curve 3 of Fig. 24, it can be concluded that the model developed in this work represents the cushioning effect correctly.

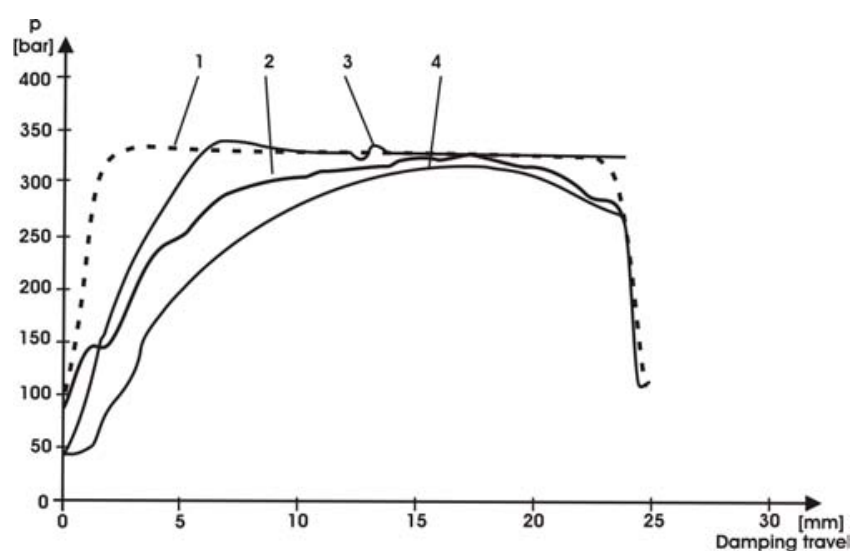

Figure 25. Behavior of the cushioning pressure for an ideal case and a real situation of application of the cushioning device (GUO, 2002).

Let's assume a working condition where the supply pressure is constant at $12 \mathrm{MPa}(120 \mathrm{bar})$, the piston speed is $0.34 \mathrm{~m} / \mathrm{s}$, the cylinder is located in a vertical line and the loading is $1200 \mathrm{~kg}$. Using the original cushioning bush and $K v \operatorname{expA}=3.5 \times 10^{-7}$ $\left(\mathrm{m}^{3} / \mathrm{s}\right) / \mathrm{Pa}^{1 / 2}$ and $K v_{\text {expB }}=1.5 \times 10^{-7}\left(\mathrm{~m}^{3} / \mathrm{s}\right) / \mathrm{Pa}^{1 / 2}$, the hydraulic cylinder speed presents the behavior shown in Fig. 25. It can be observed that the cylinder motion is not properly cushioned, since its value at stroke end is higher than $0.1 \mathrm{~m} / \mathrm{s}$, indicating the inefficiency of the cushioning bush in this situation.

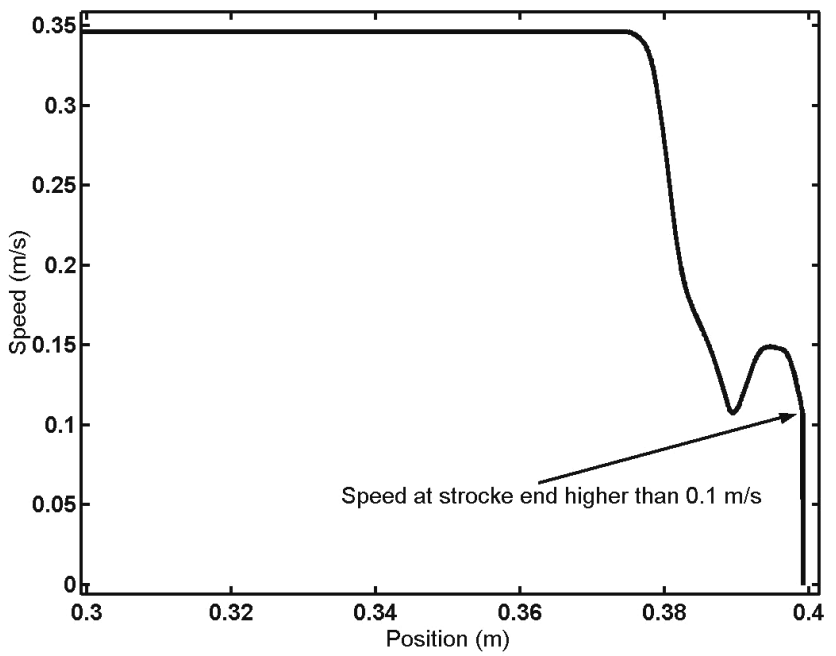

Figure 26. Simulated speed with a loading of $1200 \mathrm{~kg}$ and supply pressure of $2.1 \times 107 \mathrm{~Pa}$.

26 demonstrates, for the same operational conditions, the behavior of the pressure in the hydraulic cylinder chambers, with values higher than $30 \mathrm{MPa}$ (300 bar) being observed during the cushioning effect. Since catalogue data presents the value of $21 \mathrm{MPa}$ (210 bar) as the maximum working pressure for this hydraulic cylinder, this cushioning device is considered inadequate.

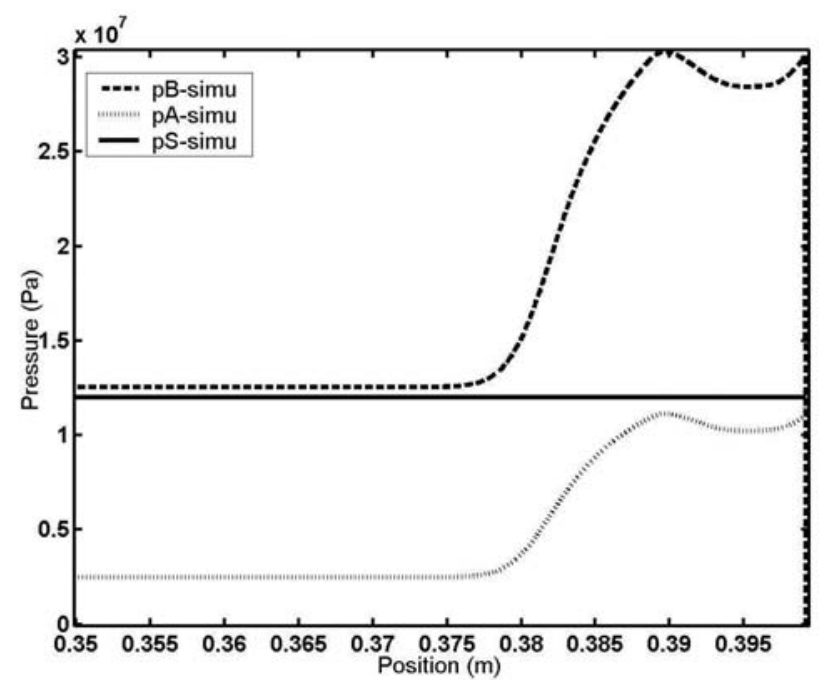

Figure 27. Simulated chamber pressures with a loading of $1200 \mathrm{~kg}$ and supply pressure of $2.1 \times 107 \mathrm{~Pa}$.

In order to provide the cushioning effect for this working condition, initially only the behavior of the cushioning factor was modified maintaining the same length in the cushioning region. As this did not give successful results, both the cushioning factor and the cushioning region length were altered. After attempting several simulations, a new cushioning bush was found which had an alteration of the cushioning region length from $24.7 \mathrm{~mm}$ to 34.2 $\mathrm{mm}$, as is shown in Fig. 27.

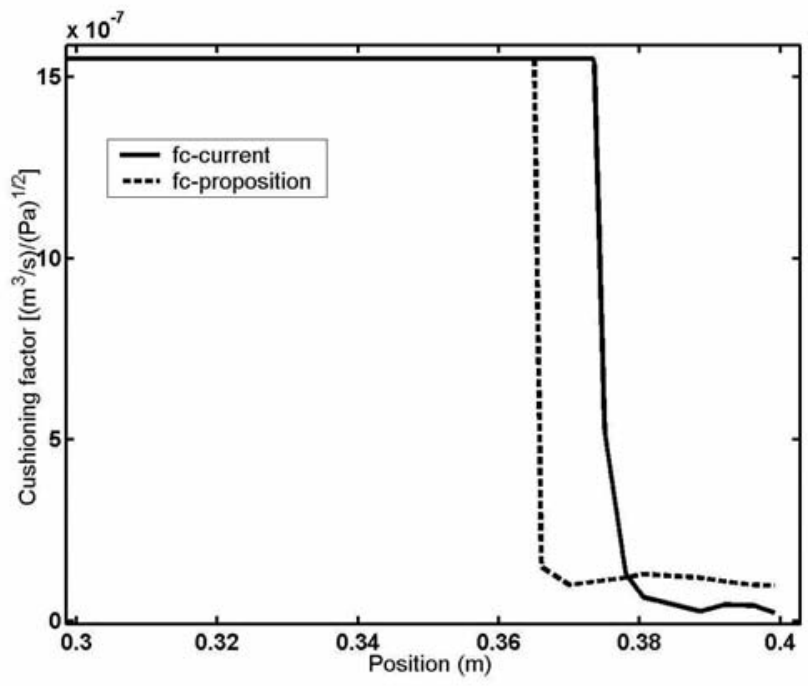

Figure 28.. New cushioning factor compared with the original one.

In Fig. 28 the piston speed behavior using this new cushioning bush can be observed. Comparing this performance with that in Fig. 25 , the new profile of the cushioning factor presents greater efficiency for these working conditions. As shown in Fig. 28 the cylinder arrived at the stroke end with a speed considerably lower than $0.1 \mathrm{~m} / \mathrm{s}$. 
Through Fig. 29 the efficiency of the new cushioning factor is established. Comparing these curves with those of Fig. 26, the pressure peak of approximately $3 \times 10^{7} \mathrm{~Pa}(300 \mathrm{bar})$ is reduced to approximately $2.1 \times 10^{7} \mathrm{~Pa}(210 \mathrm{bar})$.

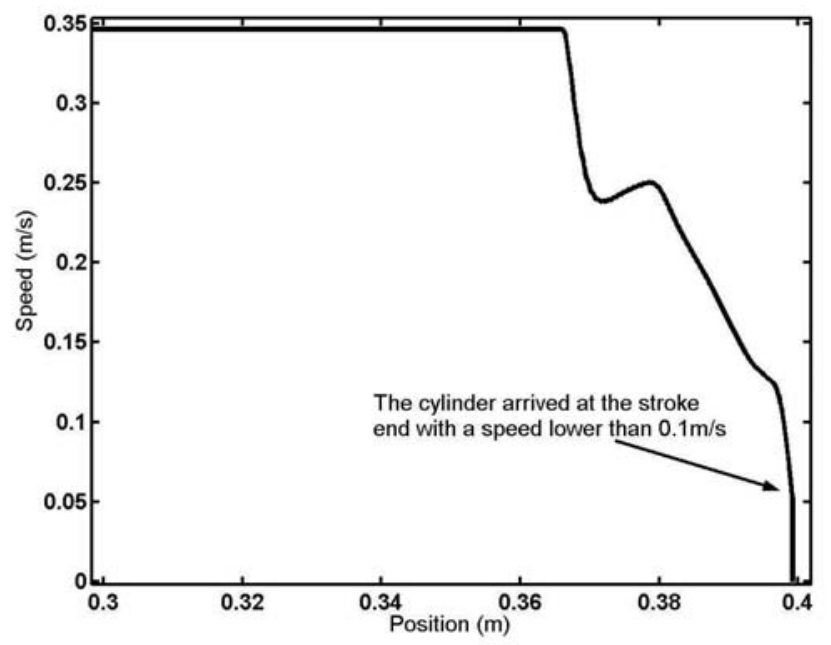

Figure 29. Simulated speed for the new cushioning factor.

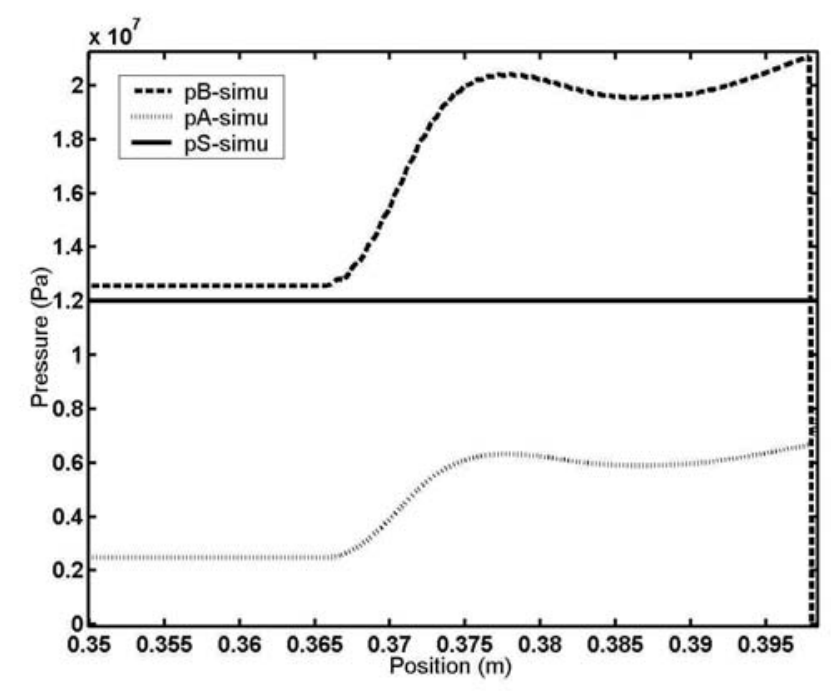

Figure 30. Simulated chamber pressures for the new cushioning factor.

\section{Conclusions}

Firstly, it can be concluded from this study that the mathematical model developed here for the cushioning device, which makes use of a factor obtained experimentally, was shown to be appropriate to describe the physical phenomenon occurring during the cushioning effect.

Some important aspects were observed during this study, such as the variation in the supply pressure, an undesirable aspect of hydraulic circuits. Thus, the supply pressure may not only affect the cushioning sizing requirements but also the performance of the hydraulic circuit. Also, it was necessity to consider the flow coefficient of proportional valves as a function of the pressure drops at the valve, in order to make detailed analyses possible.
In turn, the sensitivity of the system to possible alterations in the geometry of the cushioning bushes was observed. However, the cushioning capacity of an auto-adjustable device depends on its application. Also, it is important to consider the system performance during the design stage, in order to adequately size the cushioning bush for a given operational situation.

\section{Acknowlegments}

The authors would like to acknowledge Bosch Rexroth Ltda for financial support.

Cristiano Schwartz also thanks the CNPq, for granting him a fellowship.

\section{References}

BOSCH REXROTH, 2000. Hydraulic Cylinder CDT3, Catalog RS/E/P 17 032/051.00, Bosch Rexroth Ltda, Atibaia, S.P.

CUNHA, M. A. B., GUENTHER, R., DE PIERRI, E. R., DE NEGRI, V. J., 2002, Design of Cascate Controlers for a Hydraulic Actuator. International Journal of Fluid Power, Hamburg, Germany, n. 2, pp. 35-46.

DE NEGRI, V. J., 1987. Modeling of Hydraulic Servomechanisms and Simulation of a Mechanic-Hydraulic Servomechanism (In Portuguese), M. Sc. Thesis, Universidade Federal de Santa Catarina, Florianópolis, S.C., Brazil, $141 \mathrm{p}$.

DE NEGRI, V. J., 2001, Hydraulic and Pneumatic Systems for Automation and Control - Part III (In Portuguese), Academic Communication, Universidade Federal de Santa Catarina, Florianópolis, S.C. FOX, R. W. and McDONALD, A. T., 1995, Introduction to Fluid Mechanics. Editora Guanabara Dois, Rio de Janeiro, R.J. Brazil, 662p.

FURST, L. F., 2001, Systematization of Preliminary Design of Hydraulic Circuits with position control (In Portuguese), M. Sc. Thesis, Universidade Federal de Santa Catarina, Florianópolis, S.C., Brazil, 132p. GUO, X., 1996, Endlagendämpfung für serienmäßige industriezylinder, Internal Report, Bosch Rexroth AG., Lhor am Main, Germany.

GUO, U., 2002, Working Cylinder Actuated by Hydraulic Fluid. United States Patent, $\mathrm{N}^{\circ}$ US 6,481,331 B1.

ISO, 1991, ISO 1219-1 - Fluid Power Systems and Components: Graphic Symbols and Circuit Diagrams (Part 1: Graphic Symbols), Switzerland, $40 \mathrm{p}$.

ISO, 1995, ISO 1219-1 - Fluid Power Systems and Components: Graphic Symbols and Circuit Diagrams (Part 2: Circuit Diagrams), Switzerland, $21 \mathrm{p}$.

LINSINGEN, I. Von, 2001, Fundament of Hydraulic systems, Ed. da

UFSC, Florianópolis, S.C., Brazil, 399p.

LIE, T., CHAPPLE P. J. and TILLEY D. G., 2000, Actuator Cushion Performance Simulation and Test Results. Bath Workshop on Power Transmission and Motion Control (PTMC 2000), Bath, UK. pp. 187-198.

LI, P. Y., 2001, Dynamic Redesign of a Flow Control Servo-Valve Using a Pressure Pilot, ASME Symposium on Modeling and Control of Fluid Power Systems, New York.

MACHADO, C. L. D., 2003, Friction Compensation on Hydraulic Actuators Using Neural Nets, (In Portuguese), M. Sc. Thesis, Universidade Federal de Santa Catarina, Florianópolis, S.C., Brazil, 86 p.

MANNESMANN REXROTH, 1996, Proportional Directional Valve 4/3 and 5/3, São Paulo, S.P., Technical Catalogue RP 29113/07.96, 20 p.

MANNESMANN REXROTH, 1998, CDT3 Zugankerzylinder, Lhor am

Main, Technical Catalogue.

MATTILA J. and VIRVALO T., 2000, Energy-Efficient Motion Control of a Hydraulic Manipulator. International Conference on Robotics \& Automation, pp. 3000-3006.

MERRITT, H. E., 1967, Hydraulic Control Systems, John Wiley, USA, $358 \mathrm{p}$.

REIVAX, 2001, Data Acquisition System AQX500 - User Manual, Reivax Automação e Controle, Florianópolis.

SCHWARTZ, C., 2004, Modeling and Analysis of a Stroke End Cushioning Device for Hydraulic Cylinders, (In Portuguese), M. Sc. Thesis, Universidade Federal de Santa Catarina, Florianópolis, S.C., Brazil, 110p.

SOHL G. A., BOBROW J. E., 1999, Experiments and Simulations on the Nonlinear Control of a Hydraulic Servo System. Transactions on Control Systems Technology, pp. 238-247. 